\title{
Secretum secretorum. Joaquín de Fiore, Pedro Alfonso y la cábala
}

\author{
(1) Noeli Dutra Rossatto \\ Universidad Federal de Santa María, Brasil \\ ORCID: 000-000-0003-4176-574X
}

Recibido el 6 de marzo de 2020; aceptado el 9 de abril de 2020.

\begin{abstract}
Resumen
Dos corrientes principales dividen el debate sobre la relación entre Joaquín de Fiore (s. XII), Pedro Alfonso de Huesca (s. XI) y la cábala judaica. Gershon Scholem firma la hipótesis de que el abad de Fiore y los cabalistas españoles del siglo XII, a la vez y sin conocerse, han producido trabajos similares. Esta hipótesis será parcialmente rechazada por una segunda que pone en evidencia algunos aspectos de la obra joaquinita derivados del filósofo judío-aragonés, converso al cristianismo, Pedro Alfonso de Huesca (Moseh Sephardi). Esta segunda hipótesis permite afirmar que la explicación de la Trinidad asumida por Pedro Alfonso de acuerdo con el Tetragrama YHWH tomado del Secretum secretorum de los judíos fue incorporada por Joaquín de Fiore, y que utilizará especialmente en la composición de la Figura XIII - el Salterio de diez cuerdas, y de la Figura XI- los Tres círculos trinitarios del Liber Figurarum. Desde esta perspectiva, añadimos una tercera hipótesis: que la relación entre Joaquín de Fiore y la cábala, además de tener como punto de apoyo la explicación trinitaria de Pedro Alfonso, se refleja directamente en la confección de sus principales figurae. Y de forma complementaria, entendemos que la fuente que nutre Pedro Alfonso, e indirectamente la de Joaquín de Fiore -el llamado Secretum secretorum de los judíos- es una compilación de tres textos cabalistas principales: el Sefer Yetsirah (Libro de la Creación o del Conocimiento), el Seferal-Raziel (Libro de Raziel) y el Libro de Salomón.
\end{abstract}

PALABRAS CLAVE: JOAQUÍN DE FIORE, CÁBALA, PEDRO ALFONSO, FILOSOFÍA MEDIEVAL, SECRETUM SECRETORUM

\section{Secretum secretorum. Joachim of Fiore, Petrus Alfonsi, and the Kabbalah}

\begin{abstract}
Two lines of research dealt with the relationship between the Abbot Joachim of Fiore (12th century), Petrus Alfonsi of Huesca (11th century), and the Kabbalah. Gershon Scholem suggested the hypothesis that the Abbot of Fiore and the Spanish kabbalists of the twelfth
\end{abstract}


century simultaneously produced similar works, albeit without knowing each other. This hypothesis will be partially discarded by a second one which shows some aspects of Joachimite's work derived from the Jewish-Aragonese philosopher's one, Petrus Alfonsi of Huesca (Moseh Sephardi), who was converted to Christianity. Based on this second hypothesis, it is possible to affirm that the explanation of the Trinity that Pedro Alfonso develops from the Tetragrammaton YHWH according to the Secretum secretorum of the Jews was incorporated by Joachim of Fiore, and that will be especially used in the composition of Figure XIII-Psaltery of ten strings and Figure XI - Three Trinitarian circles. In this way, we raise a third hypothesis: that the connection between Joachim of Fiore with the Kabbalah in addition to be grounded in the Trinitarian explanation of Petrus Alfonsi, is reflected directly in the composition of its figures. Moreover, I suggest that the source on which Petrus Alfonsi is based, and indirectly Joachim of Fiore, is the Secretum Secretorum of the Jews, a compilation of kabbalists texts, among which are the Sefer Yetsirah (Book of Creation or Knowledge), the Seferal-Raziel (Book of Raziel) and the Liber of Salomonis.

ABSTRACT: JOACHIM OF FIORE, KABBALAH, PETER ALFONSI, MEDIEVAL PHILOSOPHY, SECRETUM SECRETORUM

\section{Una cuestión abierta}

Todavía hay una cuestión abierta en la historiografía joaquinita: ¿fue de hecho Joaquín de Fiore (1162-1205) influenciado por los cabalistas?

Gershon Scholem, uno de los principales estudiosos de la cábala en el siglo pasado, en su libro Las grandes tendencias de la mística judaica, publicado originalmente en 1941, sugiere la hipótesis histórica de que Joaquín y los cabalistas medievales, en especial el grupo de Girona (ciudad de Cataluña, España) y de Provenza (actual sur de Francia) del siglo XII, aunque sin conocerse, han producido cosas similares en un mismo período histórico (1996: 201). Sin embargo, a parte de la verificación de que el abad calabrés y los cabalistas medievales produjeron realmente cosas semejantes, es necesario averiguar qué aspectos de estas producciones pueden ser señalados como coincidentes en términos teóricos. Scholem, a su vez, entiende que la principal coincidencia se asienta en la afinidad entre la teoría de la historia que, en ambos los casos, menciona sucesivas manifestaciones (o emanaciones) de la divinidad en el curso del mundo. Al igual que las diez sefirot se presentan como principios de una unidad cósmica en las shemitah (ciclos de siete) y en los sucesivos eones de los cabalistas, los tres estados (status) del mundo y las siete edades (aetates) joaquinitas reproducirían una misma imagen en la historia.

Tres décadas más tarde, al intentar explicar la Figura XI, conocida como la figura de los Tres círculos trinitarios, Marjorie Reeves y Beatrice Hirsch-Reich, en un estudio cuyo título es The "Figurae" of Joaquim of Fiore (1972), retoman la hipótesis de Scholem a propósito de la estricta afinidad entre los cabalistas medievales y el abad calabrés. El punto de convergencia sería el mismo: una similar división de la historia por etapas y en simetría con un Principio trinitario, expreso como un nombre divino o una Idea de la Trinidad. Ellas también reiteran la hipótesis histórica de Scholem de que tendríamos una innegable similitud entre los escritos de los cabalistas medievales, sobre todo de los que vivieron en la Cataluña y la Provenza del siglo XII, y los del abad calabrés y sus seguidores del siglo XIII, especialmente los franciscanos espirituales.

En suma, la novedad parece ahora residir en el hecho de que Reeves y Hirsch-Reich aseguran que la composición de algunas figurae joaquinitas toman como modelo los diagramas geométricos (geometricae figurae) del judío-aragonés Moseh Sephardi (Moisés, el hispánico), que vivió en Huesca (antigua capital del Reino de Aragón), y que, tras su conversión al cristianismo, adoptó el nombre Pedro Alfonso (1062-1140). El diagrama en cuestión es la Figura XI - los Tres círculos trinitarios, que simboliza tanto la Trinidad como 
la historia dividida en tres estados, cinco tiempos y siete edades. Por lo demás, el núcleo central de la teoría de la Trinidad que sirve como apoyo doctrinal en la elaboración de esta figura también se encuentra en la explicación de Pedro Alfonso al nombre divino indicado por el Tetragrama YHWH, por él transliterado con las vocales latinas IEVE.

Son estos los principales tópicos que, a continuación, serán evaluados como posibles puntos de contacto entre Joaquín de Fiore, Pedro Alfonso y la tradición cabalista. De forma esquemática, los tópicos retomados son: 1) la explicación de la Trinidad desde el Tetragrama IEVE; 2) la FiguraXI - los Tres círculos trinitarios; y, añadimos, 3) la Figura XIII - el Salterio de diez cuerdas.

Antes de tratar los tres tópicos, presentaremos dos posiciones divergentes en la historiografía más reciente sobre la vinculación entre Joaquín de Fiore y la cábala.

\section{La cábala y el Evangelio eterno}

La primera posición se constata en una observación sucinta de Nachman Falbel, en su importante estudio Os espirituais franciscanos. Al plantear la cuestión del posible contacto entre Joaquín de Fiore y los cabalistas medievales, contesta de manera lacónica y puntual que no hay vínculo alguno entre la doctrina histórica del abad y las sucesivas fases del desarrollo cósmico de los cabalistas del siglo XIII, vislumbrada especialmente en la idea bíblica de Semithat (1995: 63).

La segunda posición proviene de un estudio más reciente, titulado La Kabbale, de Maurice-Ruben Hayoun (2011: 79-86). Al abrir esta obra nos encontramos con una sorprendente sección titulada Joachim de Flore et la doctrine des âges du monde des kabbalistes. El propio autor se pregunta: ¿por qué reservar un lugar, aunque pequeño, a Joaquín de Fiore en una obra sobre la cábala? Su contestación sigue dos caminos diferentes, aunque complementarios.

El primero de ellos parte de las fuentes de la historiografía judaica. Desde ahí argumenta que el motivo principal de la inclusión de Joaquín de Fiore en un libro que trata sobre la cábala se debe a una buena razón: aunque Joaquín jamás hubiera contactado con los grandes autores cabalistas, especialmente los anteriores al Zohar (o el Libro del Esplendor, que data del siglo XIII), ha desarrollado tesis similares, en particular en su interpretación de los textos evangélicos que, tras su muerte, fue divulgada bajo la doctrina del llamado "Evangelio eterno". Para llegar a tal conclusión, Hayoun se apoya en una obra de historia del judaísmo español escrita por Fritz Isaac Baer (Die Juden im christlichen Spanien, 1929-1936) el que, a su modo de ver, fue quien por primera vez acercó el abad de Fiore a los cabalistas medievales. Por esta misma vía, nos encontramos con la segunda hipótesis acerca de la proximidad entre ambas producciones medievales.

El segundo camino, que complementa al primero, es más específico y agrega una novedad. Al revisitar la antigua historiografía francesa sobre Joaquín de Fiore, Hayoun se detiene en el capítulo Joachim de Flore et l'Évangile éternel, del libro de Ernest Renan, Études d'histoire religieuse, de 1857. Desde allí retoma la hipótesis de que el punto de coincidencia entre las dos vertientes es el tema del Evangelio eterno. Para la hermenéutica cabalista y joaquinita, los textos revelados ya no serían tratados en términos de verdades absolutas y atemporales, sino en función de su desarrollo histórico por sucesivas etapas: los eones cabalistas y los status joaquinitas. En otras palabras, para los cabalistas, así como para Joaquín y el joaquinismo posterior, la interpretación de los textos sagrados se guiaría enteramente por la historia misma. Esta sería la justificación final de la doctrina joaquinita de un Evangelio eterno, visto como un testamento espiritual para el tercer estado del mundo. 
Es cierto que, para Joaquín y sus seguidores, el tercer estado espiritual encontraría su apogeo con la superación de la escritura histórica del Antiguo Testamento y la escritura histórico-simbólica del Nuevo Testamento. En el tercer estado ya no habría más una letra histórica o incluso una letra cifrada por enigmas y figuras. Vigorizaría la escritura espiritual sine littera, denominada por Joaquín de Fiore "Evangelio eterno" o "Evangelio del Espíritu" en sintonía con lo que prescribe el Librodel Apocalipsis 14:16 (Rossatto, 2018).

En suma, para Joaquín, el Evangelio eterno puede ser entendido en dos sentidos. En sentido hermenéutico, podría ser identificado con la interpretación espiritual de las Escrituras y de la propia historia en curso, incluso antes del ingreso en el tercer estado. En este caso, el Evangelio eterno resultaría de la aplicación del nuevo método creado por el abad: la concordia entre los dos testamentos. Para el abad, a partir de esta nueva estrategia metodológica alcanzaríamos la plena comprensión espiritual (intellectio spiritualis) ya antes del ingreso efectivo en el tercer estado del mundo.

El otro sentido resulta de una apuesta profética: cuando la humanidad ingresa en el tercer estado del mundo, un grupo de elegidos, los "hombres espirituales" (virispiritualis), destinados a protagonizar una nueva orden monástica (ordo monachorum) en la que vivirían según el Evangelio eterno o del Espíritu.

Los dos aspectos albergan el potencial revolucionario contenido en el Evangelio eterno, muchas veces identificado con la misma obra de Joaquín y algunas de ellas bajo la mirada de las condenas eclesiásticas, especialmente de la Comisión de Anagni de 1254-1255 (cf. Rossatto et al., 2010). Para otros, debido a las innumerables y repetidas tentativas de censura, de forma casi subterránea, la vertiente subversiva y heterodoxa del Evangelio eterno genera una larga posteridad espiritual que se extiende hasta nuestros días y que, en las palabras de Reeves y Gould (2000), componen el llamado "mito del Evangelio eterno".

Al final de cuentas, aunque algunas características atribuidas al Evangelio eterno, salvando pequeñas diferencias, pueden ser encontradas en las prácticas cabalistas, con ello solo comprobaríamos la antigua tesis de que Joaquín de Fiore y los cabalistas medievales vivieron en un mismo contexto histórico, que no tuvieron contacto directo entre ellos y que produjeron una hermenéutica de la historia similar.

Así pues, esta breve revisión de la literatura parece llevarnos a nuestro punto de partida. De cualquier modo, ella no resulta del todo inútil puesto que servirá de soporte para indicar con más acierto la tarea a ser emprendida de aquí por delante. En un sentido, es necesario retomar la cuestión desde su raíz y evaluar los posibles puntos de convergencia entre la producción teórica de Joaquín de Fiore y la de los cabalistas. En otro, es necesario evaluar si, de hecho, el Secretum (o Secreta) secretorum, referido textualmente por Pedro Alfonso y Joaquín de Fiore, es un texto cabalista. Solo después de este recorrido podremos sopesar la posible vinculación entre la obra de Pedro Alfonso, la de Joaquín de Fiore y la tradición cabalista.

Empecemos por el primer punto, la relación con Pedro Alfonso.

\section{Joaquín de Fiore y Pedro Alfonso}

La prueba textual de que Joaquín de Fiore ha bebido directamente de la obra de Pedro Alfonso está depositada en un pasaje de la Expositio in Apocalipsim en el que el abad, después de hacer la exegesis simbólica de las letras griegas Alfa y Omega, escribe: "Haec sacra trinitatis mysteria que in Secreta secretorum continentur apud Iudeos, 
patefecit Hebreus quidam Petrus nomine illuminatus gratia Christi et conversus a ipsum" (1964a: f. 36v) [Estos sagrados misterios de la Trinidad están contenidos en el Secreta secretorum de los judíos, y nos lo ha dado a conocer un hebreo de nombre Pedro, iluminado por la gracia de Cristo y a Él converso].

Las palabras referidas contienen tres elementos importantes en la comprobación del vínculo entre Joaquín de Fiore y Pedro Alfonso. La primera evidencia es que el abad ha leído una fuente judaica, pues ya no se duda de que el "conversus" de nombre "Petrus" es, de hecho, Pedro Alfonso (o Moseh Sephardi), que vivió en la primera mitad del siglo XII. Según los registros históricos, Pedro se convirtió al cristianismo y fue bautizado en el día de San Pedro, y su padrino fue el mismo rey aragonés Alfonso I, el Batallador. De ahí resulta su nuevo nombre cristiano. También fue él quien escribió el Dialogus contra Iudaeus, uno de los tratados del género más leído y divulgado en la Edad Media.

La segunda evidencia es que este mismo paso permite confrontar la explicación de los "misterios de la Trinidad" en ambos los autores. Joaquín de Fiore, en el mismo locus de la Expositio in Apocalipsim, y de modo más detallado en las páginas del Psalterium decem chordarum, texto en que expone especialmente su teoría trinitaria, se refiere de igual modo al nombre divino expreso en el Tetragrama IEVE (1964b: f. 257a-b; 2004: 105). Para Joaquín, el nombre de Dios, aunque tenga cuatro signos lingüísticos, está formado solo por tres letras (IEV o YHW), pues uno de los signos se repite. Además, el Tetragrama IEVE, tomado de forma integral en su composición con cuatro letras, significa la unidad substancial de la Trinidad. Sin embargo, cuando se lo considera en base a la combinación de sus cuatro letras, indica las tres personas del modo siguiente: IE=Padre, EV=Hijo y VE=Espíritu Santo (cf. Joaquín de Fiore, 1964b: ff. 228a-233b; 2004: 6-23; 1964a: f. 34Ss). Así, son tres nombres en uno, tal y como enuncia la misma fórmula trinitaria del Psalterium (1964b: 229a) de Joaquín de Fiore: "tres son uno y uno tres (tres itaque sunt unum et unum tres).

En el Dialogus contra Iudeus de Pedro Alfonso, leemos el siguiente pasaje que enseña con claridad el contenido citado por Joaquín de Fiore:

Trinitas quidem subtile quid est et inefabile et ad explanandum difficile, de qua prophetae non nisi occulte loquuti sunt et sub velamine, quoadusque venit Christus, qui de tribus una personis, fidelium illam mentibus pro eorum revelavit capacitate. Si tamen attendas subtilius et illud dei nomen, quod in Secretis secretorum explanatum invenitur, inspicias, nomen, inquam, trium litterarum quamvis quatuor figuris, una namque de illis geminata bis scribitur, si, inquam, illud inspicias, videbis, quia idem nomen et unum sit et tria. Sed quod unum, ad unitatem substantiae, quos vero tria, ad trinitatem respicit personarum (Pedro Alfonso, 1993: 110-111).

La Trinidad es algo sutil e inefable, difícil de explicar, de la cual los profetas no han hablado sino oscura y veladamente. Mas cuando vino Cristo, que es una de las tres personas, la reveló a la mente de los fieles solo en relación con su capacidad. Pero si te fijas minuciosamente en cómo está explicado el nombre de Dios en el Secreta secretorum, ese nombre, digo, se escribe con tres letras, aunque los signos sean cuatro, pues uno de ellos está repetido; si la miramos bien, repito, verás que el nombre mismo es uno y tres; uno por la unidad que significa, tres porque se refiere a la existencia trina de las personas (Pedro Alfonso, 1993: 312).

En la secuencia, Pedro Alfonso agrega que el Tetragrama está compuesto por cuatro letras, a saber: "i" ('), "e" ( $(\mathrm{I})$, "V" (I), "e" ( $(\mathrm{T})$, en donde la primera y la segunda (ie) constituyen un nombre; la segunda y la tercera (ev) otro nombre; y la tercera y la cuarta (ve) un último nombre. Pero, si visualizamos el conjunto formado por las 
cuatro letras, encontraremos un solo nombre: IEVE (cf. 1993: 312-313). Así pues, quizá se deba a Pedro Alfonso la combinación, por primera vez, de las tres semivocales hebraicas del Tetragrama asociada a cada una de las tres personas de la Trinidad, la que más tarde será incorporada por Joaquín de Fiore a su teoría trinitaria y aplicada en la teoría de la historia.

El argumento de que la Trinidad ya estaba presente de forma velada en el Antiguo Testamento no es nuevo en los tratados medievales que buscan la conversión de los judíos. El aporte original de Pedro Alfonso parece residir más bien en el descubrimiento de que la idea de Trinidad, que no es exclusivamente bíblica (pues está presente en las distintas archai de la filosofía griega -como Ser, Intelecto y Vida, por ejemplo- o en el arquetipo femenino de las religiones matriarcales que perviven como la Virgen, la Madre y la Sabia, esta última transformada en Bruja, Vieja o Prostituta), está cifrada en el Tetragrama YHWH, por él transliterado con las vocales latinas IEVE. De este modo, asociar el nombre de Dios expresado en el Tetragrama con la unidad divina, y combinar de tres modos distintos las cuatro vocales, vinculándolas a cada una de las tres personas, tal vez incluso sea la contribución más original de Pedro Alfonso, más tarde asumida por Joaquín de Fiore. De todos modos, la fuente de inspiración es una misma matriz teórica más lejana: el Secretum secretorum de los judíos.

Joaquín de Fiore, de hecho, no solo se apropiará de la explicación de Pedro Alfonso en su teoría trinitaria, sino que, en su forma gráfica, la utilizará para la confección de sus principales figurae o diagramas. La encontramos especialmente reproducida en la Figura XIII - el Salterio de diez cuerdas, que consiste en un triángulo equilátero con un círculo interior. Y además, de modo similar, aparece en el diagrama geométrico formado por las letras Alfa (A), con formato triangular, y Omega (O), en su forma circular, de la que resulta la misma forma del salterio. En el vértice superior del triángulo aparecen las letras IE, indicando el Padre; en el vértice inferior de la izquierda EV, para el Hijo; y en el vértice inferior de la derecha VE, para el Espíritu Santo. En el círculo central del triángulo se encuentra el nombre divino IEVE, que remite a la unidad substancial de la Trinidad.

La misma matriz teórica utilizada por Pedro Alfonso en la explicación de la Trinidad se volverá a encontrar en su forma visual en la Figura XI - los Tres círculos trinitarios. En el interior de los tres círculos entrelazados están grabados el nombre divino IEVE, representando la unidad substancial, y las cuatro vocales (I-E-V-E), distribuidas en cada uno de los sucesivos estados, de acuerdo con las manifestaciones históricas del Padre (I), del Espíritu (E), del Hijo (V) y del Espíritu (E). Tal figura significa, por imagen y por similitud, los diferentes pasos de las generaciones paternas, filiales y espirituales, distribuidos a lo largo de la historia y en conformidad con el nombre divino del Tetragrama IEVE.

A la argumentación que aproxima de forma comparativa la explicación de la Trinidad por Pedro Alfonso y Joaquín de Fiore, podemos agregar otro elemento significativo a modo complementario. La figura triangular del Salterio de diez cuerdas, que es la Figura $X I$ del Liber Figurarum de Joaquín reproduce innegablemente el diagrama geométrico creado por Pedro Alfonso para explicar a la Trinidad (cf. Bittonti y Oliverio, 1998). Es el diagrama en el que cada uno de los vértices del triángulo equilátero está formado por un pequeño círculo. En el interior de cada círculo, a su vez, encontramos las combinaciones de las letras IE-EV-VE, cada una de ellas asociada a una de las personas de la Trinidad. En el centro del triángulo está inscrito el nombre divino IEVE, señalando así la esencial unidad divina (cf. Pedro Alfonso, 1993: 313).

Veamos abajo, lado a lado, las figuras trinitarias de Pedro Alfonso y Joaquín de Fiore: 


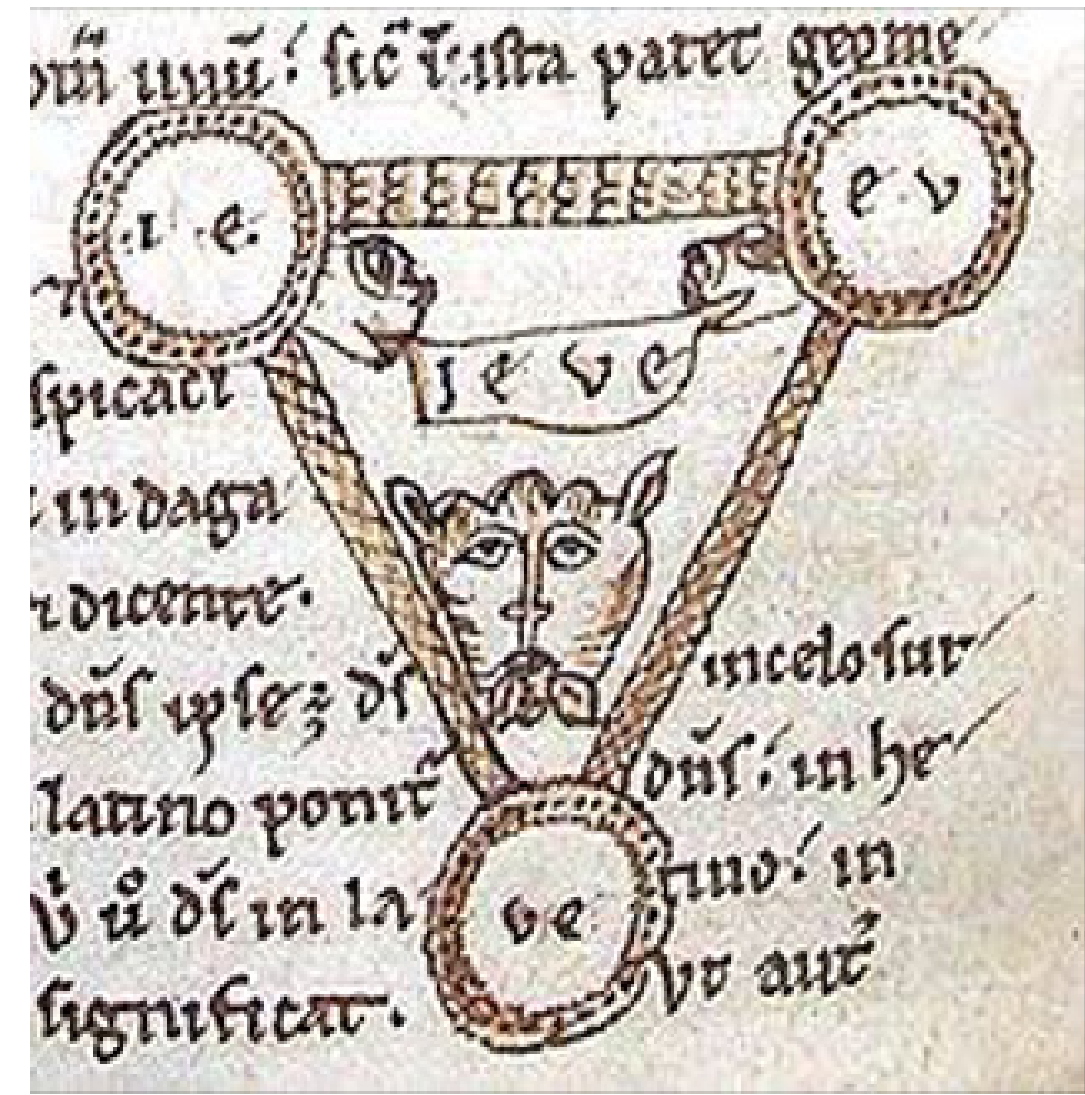

Pedro Alfonso ${ }^{1}$

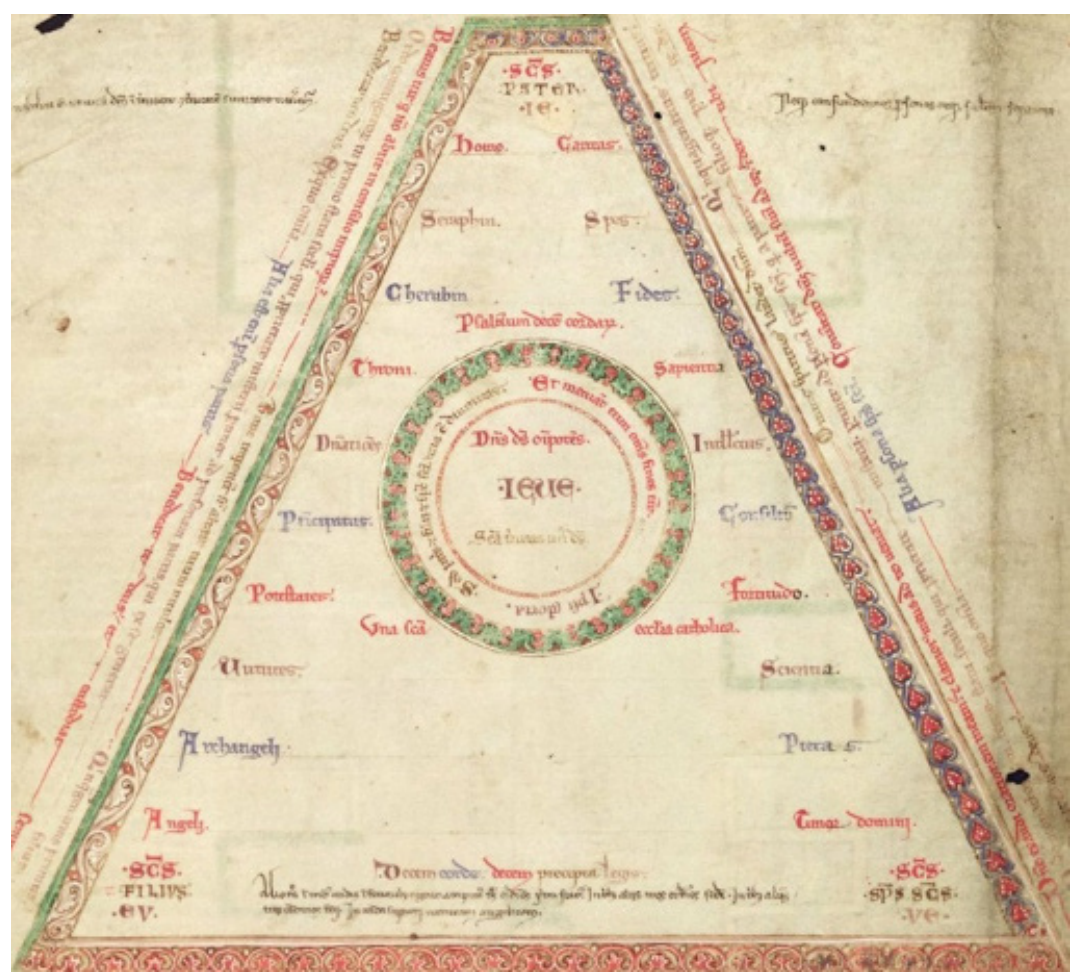

Joaquín de Fiore ${ }^{2}$

1 Imagen pertenecienete al Cambridge, St John's College, Ms. E. 4, f. $153 \mathrm{v}$.

2 La Figura XIII de Joaquín de Fiore fue tomada de Oxford, Corpus Christi College, Ms. 255A, f. 8r. 
Además de las innegables similitudes, hay que notar que los dos diagramas están en una disposición contraria. En la primera figura, hay un triángulo equilátero con el vértice apuntando hacia abajo; en la segunda, el vértice se vuelve hacia arriba. La disposición contraria de las dos figuras puede indicar algo significativo en la comparación entre los dos autores y la paradigmática figura del Árbol de la vida cabalista. El diagrama de Pedro Alfonso retrata las tres sephiroth que, como segunda secuencia de tríadas en el Árbol de la vida, están relacionadas con el Cosmos, a saber: Geburah, Hésed, Tiphéret; mientras que en Joaquín de Fiore corresponde a las tres primeras sephiroth, indicadoras de las tres hipóstasis divinas, a saber: Kether, Hokmah, Binah.

Igual comparación resulta de las dos figuras circulares de los autores. Una es la conocida Figura XI - los Tres círculos trinitarios de Joaquín de Fiore cuya versión del Oxford, Corpus Christi College, Ms. 255A, f. $7 \mathrm{v}$ reproducimos abajo. La otra es una figura similar propuesta por Pedro Alfonso (1993: 313) en su Dialogus contra Iudeus, formada por tres pequeños círculos de igual diámetro, representando las tres personas de la Trinidad. De los tres pequeños círculos, dos se tocan externamente; un tercero está trazado sobre los demás. Un cuarto círculo de mayor diámetro envuelve a los tres menores, significando la unidad substancial. En el interior de cada uno de los tres círculos más pequeños están inscriptas en caracteres hebraicos las cuatro letras del Tetragrama.

Aunque Joaquín de Fiore no haga mención explícita al diagrama de Pedro Alfonso, como lo hará en el caso de la explicación de la Trinidad con base en el Tetragrama IEVE, difícil será no encontrar ahí la fuente inspiradora de la figura joaquinita de los tres círculos trinitarios. Sin embargo, es necesario notar los detalles que distinguen las dos imágenes trinitarias. El primer detalle consiste en la eliminación del círculo exterior de mayor diámetro en el diagrama de Pedro Alfonso. Para el abad de Fiore, ello ciertamente podría indicar un cuarto término, lo que conllevaría al error del arrianismo o cuaternarismo ya censurado por el abad en la enunciación trinitaria del magister Pedro Lombardo, lo que, en cambio, resultará en la condena de su propia doctrina trinitaria en el IV Concilio Lateranense de 1215.

El segundo detalle reside en la disposición gráfica de los tres círculos. En Joaquín, los tres círculos están entrelazados de tal forma que muestra la perfecta simetría entre ellos, y además permite visualizar no solo la unidad trinitaria ubicada en el centro, sino también -y en igual medida-identificar lo que es propio a cada una de las personas trinitarias en particular. El resultado es la Figura XI - los Tres círculos trinitarios (abajo a la derecha), tal como aparece en el Liber Figurarum y en la Expositio in Apocalipsim, que es, a la vez, la misma imago de la historia.

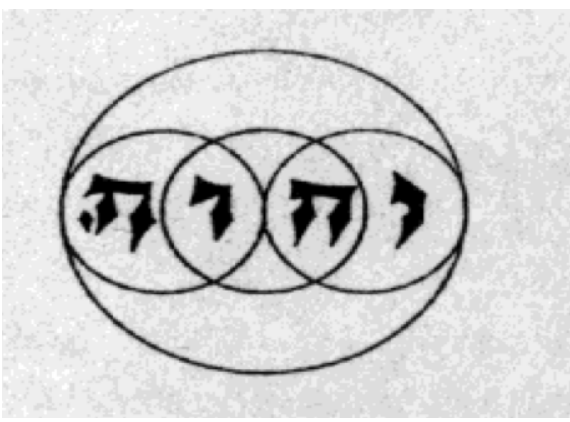

Pedro Alfonso

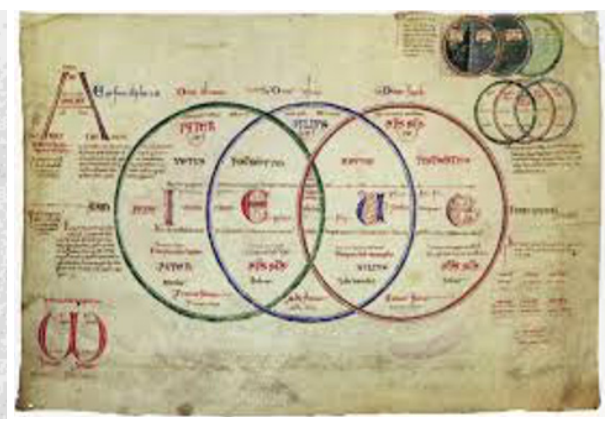

Joaquín de Fiore

Así pues, pasemos ahora a avaluar el tercer aspecto destacado en Pedro Alfonso y Joaquín de Fiore: el célebre Secretum secretorum de los judíos. En nuestra investigación, es este el punto decisivo para establecer el posible vínculo entre el abad de Fiore y la tradición cabalista judaica. 


\section{El Secretum secretorum de los judíos}

Ya hemos visto que el punto de enlace entre Joaquín de Fiore, Pedro Alfonso y el Secretum secretorum de los judíos es la explicación del Tetragrama IEVE. A este respecto, las palabras de Pedro Alfonso advierten que, si nos detenemos en la explicación del nombre divino que se halla en el Secretum secretorum de los judíos, encontraremos la misma doctrina trinitaria. Para nosotros, la forma en que Pedro Alfonso explica el nombre divino se remonta a una especie de enigma indicador del singular modus operandi de los cabalistas.

Dos son las cuestiones evocadas por el supuesto enigma: a) ¿cuál es el nombre divino que se escribe con cuatro signos lingüísticos pero contiene solo tres letras?; y b) ¿cuál es el nombre divino que forma otros tres nombres a partir de la combinación de sus distintos signos lingüísticos? En ambos casos, la respuesta es una solo: el nombre divino es el Tetragrama IEVE.

En respuesta a la primera cuestión, las tres letras son tomadas de modo conjunto como un solo nombre, compuesto, así, por las letras IEV (o YHW), pues aunque sea escrito con cuatro signos lingüísticos (IEVE o YHWH), uno de ellos se repite. En la segunda cuestión, la contestación es que los tres distintos nombres divinos son alcanzados por las combinaciones de las cuatro letras, del siguiente modo: IE para Padre; EV para Hijo; y VE para Espíritu Santo.

Según lo que llevamos dicho, Joaquín asume la revelación de este enigma desde la explicación de la Trinidad hecha por Pedro Alfonso. Lo que todavía no ha sido suficientemente contestado es la siguiente cuestión: ¿qué es el misterioso texto llamado Secretum secretorum? Y, más aún: ¿el texto es realmente una fuente cabalística? Para contestar estas cuestiones, debemos examinar antes algunas opiniones especializadas respecto del Secretum secretorum de los judíos.

La primera opinión que examinaremos proviene de la introducción a la edición castellana del Dialogus contra Iudeus de Pedro Alfonso. En su introducción a la obra, John Tolan hace dos observaciones puntuales en relación con el Secretum secretorum (1993: xlii-xliv). En un sentido, que para nosotros es correcto, él entiende que la explicación de la Trinidad cristiana con arreglo al nombre de Dios del Tetragrama IEVE es una contribución original de Pedro Alfonso. En otro, añade que el Secretum secretorum tal vez sea efectivamente un texto cabalista, y observa que la obra no debe ser confundida con la carta apócrifa de Aristóteles a Alejandro Magno, conocida en la Edad Media por igual nombre (cf. Pseudo-Aristóteles, 2010; Martins, 2013).

La segunda opinión es la de Viviente-Mateu. En su breve artículo "Pedro Alfonso y la iconografía religiosa europea" añade un paso más en la discusión al sugerir que, independientemente de la originalidad de la explicación trinitaria de Pedro Alfonso, su motivación proviene del Sefer Yetsirah (Libro de la creación o del Conocimiento), escrito entre los siglos VI y VII, y citado como el Secretum secretorum de los judíos (2003: 31).

A su vez, la historiografía joaquinita especializada identifica el Secretum secretorum con otra fuente cabalista. Marjorie Reeves y Beatriz Hirsch-Reich, al comentar la Figura XI - los Tres círculos trinitarios del Liber figurarum -que ha sido atribuido a la escuela joaquinita del siglo XIII, pero mantiene fidelidad a su autor- sugieren que el Secretum secretorum mencionado por Pedro Alfonso y Joaquín de Fiore es un libro mágico-místico, también llamado Libro de Raziel, del cual quedan pocas páginas (1972: 41). Tal vez en este caso las autoras tengan en mente el libro de igual título hebreo, Sefer Há-Razin (conocido como Libro de los secretos), probablemente escrito en el siglo III. Sin embargo, distinto de este resulta ser el Sefer Razielis, traducido al 
latín con diferentes títulos, entre ellos: Liber Razielis, Liber Salomonis, Liberinstitutiones o Volumina Salomoni. Estudios recientes, además de conceder que el segundo libro proviene del primero, afirman que el Secretum secretorum del que habla Pedro Alfonso es, en verdad, el Sefer Há-Razin, y este sí sería una fuente judaica más antigua (cf. García-Avilés, 1997; González-Sánchez, 2010).

En cualquier caso, volvemos a la cuestión inicial. ¿Sería el misterioso Secretum secretorum de los judíos el Sefer Há-Razin, tal como pretenden algunos? O, como aseguran otros, ¿sería el Sefer Yetsirah? Y más aún: ¿estaríamos ante una fuente cabalista?

Parece que la respuesta más completa a este asunto es la de Alfred Büchler (1986), posteriormente asumida por el estudioso de la obra del abad calabrés, Bernard McGinn en Cabalists and Christians: reflextions on cabala in Medieval and Renaissance Thoughty (1994). En síntesis, McGinn concluye que el Secretum secretorum es una compilación de partes de textos provenientes de tres fuentes judaicas principales, a saber: 1) la obra de magia conocida como Sefer Há-Razin; 2) el famoso texto esotérico conocido como Sefer Yetsirah; y 3) algunos fragmentos de textos alquímicos.

La consistencia de esta respuesta se debe principalmente a que ella consigue abarcar las hipótesis anteriores. Por nuestra parte, en lo que toca a saber cuál es el texto concreto del Secretum secretorum que enseña el locus citado por Pedro Alfonso -y después retomado por Joaquín de Fiore- en la explicación de la Trinidad y en la composición de los distintos diagramas geométricos o figurae, entendemos que se trata del Sefer Yetsirah. Dos razones principales nos llevan a tal conclusión.

La primera resulta de la coincidencia entre los contenidos del Sefer Yetsirah y del Dialogus contra Iudeus de Pedro Alfonso. En particular, el final del Libro I del Sefer Yetsirah donde, en una exposición bastante enigmática, señala que las tres letras (YHV) del poderoso nombre de Dios, allí llamadas de mater lectionis, sirven para sellar las seis dimensiones del mundo (2013:54-56). Los seis sellos están enmarcados por distintas combinaciones de las tres letras del nombre divino del Tetragrama, del siguiente modo: 1) YHV, 2) YVH, 3) HYV, 4) HVY, 5) VYH, 6) VHY. Pedro Alfonso sin duda utiliza de este mismo procedimiento cuando explica las tres personas de la Trinidad. No obstante, no mantiene las combinaciones por conjuntos de tres letras, sino que, en su lugar, adopta un modelo binario: 1) YH (ie), 2) HV (ev), 3) VH (ve). Tampoco conserva la misma secuencia numérica limitada por el número seis de acuerdo a las seis dimensiones del Mundo. Ahora el reto es otro: explicar la tríada personal de la Trinidad y no ya el Mundo, como sucede en la fuente cabalista.

La segunda razón reside en el procedimiento formal adoptado por Pedro Alfonso. En comparación con el Sefer Yetsirah, la originalidad de Pedro Alfonso no consiste propiamente en haber tomado el Tetragrama YHVH y después dividirlo en consonancia con las seis dimensiones del Mundo, lo que no habría sido más que repetir el texto del Secretum secretorum. Su originalidad consiste precisamente en aplicar el modelo del Sefer Yetsirah (de acuerdo con la compilación del Secretum secretorum) en la explicación de la teoría trinitaria. Dicho de otro modo, consiste en asociar el nombre divino IEVE a la unidad substancial, y las tres combinaciones de las letras del nombre divino a la tríada personal.

Joaquín de Fiore, a su vez, adopta ipsis litteris el mismo procedimiento de Pedro Alfonso en su teoría trinitaria. También asume como suyos, aunque no sin los debidos reparos, dos de los diagramas geométricos de Pedro Alfonso, a los cuales nos hemos referido anteriormente, ambos forjados con arreglo al mismo procedimiento de explicación de la Trinidad. Al respecto, es necesario observar que la vinculación con Pedro Alfonso no habría llevado a Joaquín al error trinitario señalado por el IV 
Concilio Lateranense de 1215, como erróneamente insisten algunos. El abad hace correcciones significativas en los diagramas del judío aragonés para adecuarlos a la doctrina trinitaria canónica de los círculos cristianos y monásticos de su entorno. En este sentido, según juzgamos, no es correcto decir que hay propiamente un error en la teoría trinitaria de Joaquín, como muchos pretenden. Solamente encontramos errores desde la sesgada perspectiva escolástica que se fortalece durante el siglo XIII (en especial con el ascenso de Inocencio III al papado, que antes de clérigo era un conde), y que en todo se alejaba de la tradición monástica y más aún del modelo de pensamiento de corte griego clásico (cf. Rossatto, 2004).

Finalmente, queda por saber si, de hecho, el Sefer Yetsirah es un texto cabalista.

\section{Conclusiones}

A juzgar por la opinión de estudiosos como Scholem (2001: 27) y Forcano (2013), entre otros, el Sefer Yetsirah es un texto protocabalista. ¿Qué quiere decir eso precisamente? En primer lugar, quiere decir que la cábala propiamente dicha fue compuesta en el decurso de la Edad Media; y, en segundo lugar, que el Sefer Yetsirah ha contribuido decisivamente en su configuración final, actual y más popularizada. Otros como McGinn (1994) y Viviente-Mateu (2003), en cambio, lo consideran sin problemas como un texto cabalista.

En la confección de la cábala se destaca en particular, a nuestro juicio, el Libro I del Sefer Yetsirah, pues ya dibuja los trazos básicos de un sistema triangular estructuralmente formado por los diez números primordiales y las veintidós letras del alfabeto hebraico, es decir, números y letras. El Espíritu de Dios ocupa el lugar más alto. Las tres letras del alfabeto hebraico componen las casas superiores siguientes: Alef (el Aire que viene del Espíritu de Dios); Mem (el Agua que viene del Aire); Shin (el Fuego que viene del Agua). A los cuatro elementos primordiales, en general derivados de la cosmología platónica del Timeo, se suman las seis dimensiones del Mundo, resultando en la década pitagórica. Aquí, quizás por vez primera, los diez números primordiales están asociados a las diez sefiroth, lo que no solo prepara sino también hilvana los nudos principales del diseño gráfico de lo que más tarde será conocido como el Árbol de la vida cabalista.

Sabemos que el Árbol de la vida está formado por diez sefiroth -que son seres numéricos- y veintidós caminos o letras del alfabeto hebraico. Así, la creación del mundo (Maasé Bereshi), que resulta de la mezcla de números y letras, se efectiviza mediante treinta y dos caminos misteriosos de sabiduría, los Caminos de la gloria, los cuales, según la herencia neopitagórica de Nicómaco de Gerasa, señalan el número de la rectitud en base a su infinita divisibilidad. De igual suerte, los cuatro elementos primordiales están vinculados a la Visión del carro o Maasé Merkabá, que reaparece a lo largo de la Edad Media en la composición de la figura de los cuatro animales: el Águila (Aire), el Ángel u Hombre en azul (Agua), el León (Fuego) y el Toro (Tierra). Igual diagrama está reproducido en las representaciones medievales del arte románico, como la figura del mundo o pantocrátor, así como también en su versión renacentista en la carta veintiuno (El Mundo) del Tarot de Marsella. A su vez, las seis dimensiones del Mundo en el Sefer Yetsirah están vinculadas a la Maasé Bereshi o Relato de la creación que es uno de los temas que reúne la cosmogonía griega platónica, neoplatónica y neopitagórica con la tradición judaica y cristiana.

En Joaquín de Fiore veremos estas secuencias numéricas en la estructuración de los tres árboles genealógicos, la paterna, la filial y la espiritual, que componen los tres estados del mundo. Las generaciones están distribuidas en tres listas exactas 
de veintiún personajes en cada uno de los tres estados del mundo. La secuencia encabezada por el número veintiuno puede también haberse inspirado, además del pasaje del Evangelio de Mateo 1:1 que sugiere la división por conjuntos numéricos de cuarenta y dos generaciones en la genealogía de Jesús (formado así: 14+14+14), en la suma resultante de las tres letras hebraicas que componen el nombre divino YHW $(\mathrm{Y}=10 ; \mathrm{H}=5 ; \mathrm{W}=6)$. Dos secuencias de veintiuna generaciones son iguales a la suma de los diez números primordiales más las veintidós letras del alfabeto, los tres cielos y los siete planetas: $10+22+3+7=42$. Además, se sabe que para el abad de Fiore cuarenta y dos generaciones de treinta años cada una $(42 \times 30)$ resultan en el enigmático número 1260. Más precisamente, Daniel 7: 23-25 y Apocalipsis 12:24 hacen referencia a "un tiempo, dos tiempos y la mitad de un tiempo" que, tomando como base el año perfecto de 360 días, resulta: $360+360+360+180=1260$.

Concluimos, así, que Joaquín de Fiore, mediante la lectura de la obra de Pedro Alfonso, fue influenciado indirectamente por un texto protocabalista o cabalista que utilizará en la composición de su teoría trinitaria. Además de adoptar esa matriz cabalista en la composición de su teoría trinitaria con arreglo al nombre de Dios del Tetragrama IEVE, el abad también la utilizará en la confección de algunas de sus principales figurae. En especial, notamos esta influencia en la composición de la Figura XI - los Tres círculos trinitarios y en la Figura XIII - el Salterio de diez cuerdas. También notamos alguna similitud con las figuras de los árboles genealógicos del Padre, del Hijo y del Espíritu Santo (Figuras II, V, VI del Liber Figurarum) y la figura del Mundo (Figura XV) que no tratamos aquí.

Por lo demás, queda todavía por investigar posibles vinculaciones más estrictas entre Pedro Alfonso y los cabalistas españoles medievales. También queda por averiguar hasta qué punto el empleo de los números y de la proporción numérica en la lectura del texto bíblico y de la historia, según el método per concordia de Joaquín de Fiore, proviene o no de los procedimientos cabalistas. 


\section{Dibliografía}

\section{Fuentes}

\section{Manuscritos}

》Cambridge, St John's College, Ms. E. 4.

»Oxford, Corpus Christi College, Ms. 255A.

\section{Ediciones}

"Anónimo (2010). Liber Salomonis. Cephar Raziel. Transc., notas e intr. Karr, D. Singapur: Golden Hoard Press.

»Anónimo (2013). Libro de la creación. Ed. y trad. Forcano, M. Barcelona: Fragmenta Editorial.

" Joachim Florensis (1964a). Expositio in Apocalypsim (con Liber introductorius in Apocalipsis). Ed. Venecia 1527; reimp. facs. Frankfurt a. M.: Minerva.

" Joachim Florensis (1964b). Psalterium decem chordarum. Ed. Venecia 1527; reimp. facsi. Frankfurt a. M.: Minerva.

"Pedro Alfonso de Huesca (1993). Diálogos contra los judíos. Intr. Tolan, J., Texto lat. Mieth, K.-P., trad. Ducay, E. Huesca: Instituto de Estudios Altoaragoneses.

\section{Traducciones}

"Anónimo (1992). Sefer Yetzirah. Trad. Eisenfield, M. Barcelona: Obelisco.

» Anónimo (2005). Sêfer letsirá. O livro da criação - teoria e prática. Trad. Kaplan, A. San Pablo: Sêfer.

" Gioacchino da Fiore (2004). Il salterio a dieci corde (Psalterium decem chordarum). Trad. Troncarelli, F., Rev. Selge, K.-V. Roma: Viella. (Opere di Gioacchino da Fiore: testi e strumenti 16).

"Pseudo-Aristóteles (2010). Secreto de los secretos. Poridat de las poridades. Ed. Bizzarri, H. Valencia: PUV. (Parnaseo 12).

\section{Bibliografía complementaria}

" Baer, F. I. (1929-1936). Die Juden im christlichen Spanien. Berlin: Akademie Verlag vol. 1/ Schocken, vol. 2.

" Bitonti, M. y Oliverio, S. (1998). Gioacchino: Abate di Fiore. San Giovanni in Fiore: Edizioni Pubblisfera.

" Büchler, A. (1986). "A Twelfth-Century Physician's Desk Book: The Secreta secretorum of Petrus Alphonsi Quondam Moses Sephardi", Journal of Jewish Studies 37, 206-212.

» Falbel, N. (1995). Os espirituais franciscanos. San Pablo: Edusp - Fapesp - Perspectiva. 
» Falbel, N. (2018). "Sêfer letzirá (Livro da Criação), Sêfer Há-Bahir (Livro da Claridade) e Sêfer Há-Zohar (Livro do Esplendor)", Scintilla 15.1, 57-87.

» Forcano, M. (2013). "Introducción”. En: Anónimo. Libro de la creación. Ed. y trad. Idem. Barcelona: Fragmenta Editorial, 9-48.

" García-Avilés, A. (1997). "Alfonso X y el Liber Razielis. imágenes de la magia astral judía en el scriptorium alfonsí", Bulletin of Hispanic Studies 74.1, 21-40.

"González-Sánchez, A. R. (2010). "El Liber Razielis alfonsí en su contexto hebreo", Espéculo. Revista de Estudios Literarios 46, 23-45.

" Hayoun, M.-R. (2011). La kabbale. París: Ellipses Éditions Marketing.

" Martins, M. M. B. (2013). "O Secretum secretorum na edição de Roger Bacon: significação dos segredos e enigmas do conhecimento". Mediaevalia. Textos e Estudos $32,105-122$.

" McGinn, B. (1994). "Cabalist and Christians: Reflections on Cabala in Medieval and Renaissance Thought". En: Popkin, R. H. y Weiner, G. M. (eds.). Jewish Christians and Christians Jews. From the Renaissance to the Enlightenment. Nueva York: Springer, 11-34.

»Reeves, M. y Gould, W. (2000). Gioacchino da Fiore e il mito dell'Evangelo eterno nella cultura europea. Roma: Viella. (Opere di Gioacchino da Fiore: testi e strumenti 12).

»Reeves, M. y Hirsch-Reich, B. (1972). The Figurae of Joaquim of Fiore. Oxford: Clarendon Press.

» Renan, E. (1857). Études d'histoire religieuse. París: Michel Lévy Frères.

» Rossatto, N. D. (2004). Joaquim de Fiore: Trindade e Nova era. Porto Alegre: EDIPUCRS.

» Rossatto, N. D. (2018). "Hermenêutica e fim da história", Trans/Form/Ação 41.1, 61-80.

» Rossatto, N. D. et al. (2010). "Evangelho eterno: a hermenêutica condenada. Com tradução das Atas do Protocolo de Anagni - 1255-56". Filosofia Unisinos 11.3, 298338.

» Scholem, G. (1996). Las grandes tendencias de la mística judaica. Trad. Oberländer, B. Madrid: Siruela.

»Scholem, G. (2001). Los origines de la cábala. Werblowsky, R. J. (comp.), Molina, R. y Mora, C. (trads.). Barcelona: Paidós.

" Tolan, J. (1993). "Introducción". En: Pedro Alfonso de Huesca. Diálogos contra los judíos. Huesca: Instituto de Estudios Altoaragoneses, ix-lvii.

"Viviente-Mateu, J. L. (2003). "Pedro Alfonso y la iconografia religiosa europea", Revista Española de Filosofía Medieval 10, 29-43. 